\title{
EL GIRO EPISTEMOLÓGICO EN LA UNIVERSIDAD AGRARIA DE LA HABANA (UNAH), CUBA
}

\author{
THE EPISTEMOLOGICAL TURN OF THE AGRICULTURAL \\ UNIVERSITY OF HAVANA (UNAH) \\ O GIRO EPISTEMOLÓGICO NA UNIVERSIDAD \\ AGRARIA DE LA HABANA (UNAH), CUBA
}

\author{
Adolfo Ramos Lamar ${ }^{1}$ \\ Eduardo Fracisco Roach ${ }^{2}$
}

\begin{abstract}
RESUMEN: En la Epistemología articulada en la Educación Superior Agropecuaria en Cuba antes de 1990 intervienen la política agraria, la política científica y tecnológica, y la política de educación superior. El objetivo del presente trabajo consiste en abordar cómo en el Complejo Científico Docente Universidad Agraria de la Habana (UNAH) viene abriéndose paso una Epistemología en sintonía con el rumbo de la política agraria. Un indicador de ese giro epistemológico son las concepciones de la ciencia y la tecnología emergentes del rediseño de los planes y programas de las carreras de ciencias agropecuarias. En este sentido, si bien emerge un escenario favorable, no es menos cierto que ya existía en nuestro ámbito académico una masa crítica de profesores cuyos trabajos de investigación y su labor docente anuncian la necesidad de ese giro epistemológico.
\end{abstract}

PALABRAS CLAVE: Epistemología. Educación agraria superior. Cuba. Revolución verde. Agricultura sostenible.

ABSTRACT: The Epistemological turn of the agricultural higher education in Cuba, before 1990 were involved the Agricultural policy, scientific and Technological policy, and Higher education policy. The objective of the present work is to analyze how the Epistemology in harmony with the direction of the agrarian policy is being developed in the Scientific University Complex of Havana (UNAH). An indicator of this epistemological turn is the conceptions of Science and Technology emerging from the redesign of the plans and programs of the agricultural sciences careers. In this sense, although a favorable scenario emerges, it is no less true that a critical mass of teachers already exists in our academic field, whose research and teaching work herald the necessity of this Epistemological Turn.

KEYWORDS: Epistemology. Higher agrarian education. Cuba. Green revolution. Sustainable agriculture

RESUMO: Na Epistemologia existente na Educação Superior Agropecuária em Cuba antes de 1990 intervém a política agraria, a política científica e tecnológica e a política de educação superior. $\mathrm{O}$ objetivo do presente trabalho consiste em abordar como no Complejo Científico Docente Universidad Agraria de la Habana (UNAH), Cuba, vem ocupando espaço uma Epistemologia em sintonia com o rumo da política agrária. Um indicador desse giro epistemológico são as concepções da ciência e da tecnologia emergentes da reformulação dos planos e programas dos cursos de ciências agropecuárias. Nesse sentido, ainda que venha à tona um cenário favorável é necessário colocar que já existia no âmbito acadêmico uma massa crítica de professores que com seus trabalhos de pesquisa e seu trabalho docente anunciam a necessidade desse giro epistemológico.

PALAVRAS-ChAVE: Epistemologia. Educação agrária superior. Cuba. Revolução verde. Agricultura sustentável.

Presentando en: 18/10/2017 - Aceptado en: 03/04/2018 - Publicado en: 11/04/2018

\begin{tabular}{l|l|l|l|l|l}
\hline (C) Rev. Inter. Educ. Sup. & Campinas, SP & v.4 & n.2 & AOP & mayo/ago. 2018
\end{tabular}




\section{INTRODUCCIÓN}

Las políticas agrarias establecen un conjunto de pautas, regulaciones, marcos institucionales, y decisiones sobre la tenencia y uso agrícola de la tierra y el papel de la actividad agrícola en el bienestar alimentario, económico y cultural de un país. Pero para proyectar y lograr esos propósitos las políticas agrarias demandan una construcción loable del conocimiento de la realidad agrícola y su transformación a través de las actividades de ciencia y tecnología en diversos escenarios, en especial, en educación (BREILH, 2005).

Determinados presupuestos epistemológicos operan en las actividades de ciencia, tecnología y educación ${ }^{2}$ y suele suceder que se asuman "sin total claridad" (GUADARRAMA GONZÁLEZ, 2017, p. 27). Por otro lado, en las comunidades científicas se manifiestan rivalidades epistemológicas ${ }^{3}$. Circunstancias sociales, económicas y políticas condicionan la reluctancia o recepción de determinada epistemología. Por ejemplo, no es un secreto que los ideales epistemológicos fundamentados en la Filosofía de la Ilustración y la Filosofía Positivista tributan a las políticas de modernización agraria que responden al proyecto económico, político, social y cultural de la burguesía y el capitalismo.

Dinámica epistemológica particular tiene lugar en la elaboración e implementación de las políticas de ciencia, tecnología y educación, en función del desarrollo agropecuario en Cuba (FREYRE ROACH; RAMOS LAMAR, 1994; RAMOS LAMAR, 1995).

En este contexto, la enseñanza universitaria de contenidos filosóficos y epistemológicos resulta imprescindible en "la formación humanística e integral de los futuros profesionales" (SEVERINO, 2012, p. 21). Esto es indispensable para lograr los propósitos previstos a corto y largo plazo. Hoy en día se hace necesario derribar ciertas barreras epistemológicas que frenan el desarrollo sustentable de la agricultura (CAROLAN, 2009).

El objetivo del presente trabajo consiste en abordar cómo a partir de 1990 en el Complejo Científico Docente Universidad Agraria de la Habana (UNAH), Cuba, viene abriéndose paso una epistemología en sintonía con el rumbo que ha tomado la política agraria y el rediseño de los planes y programas de las carreras de ciencias agropecuarias. El trabajo es resultado de

\footnotetext{
${ }^{2}$ Epistemología no es un término tan antiguo, tampoco lo que designa (BLANCHÉ, 1988). Literalmente alude a Teoría de la Ciencia (Wissenschaftstheorie). Su introducción se le atribuye al filósofo escocés James Frederick Ferrier que en 1854 propuso dividir la Filosofía en Ontología y Epistemología. Es recurrente en la filosofía burguesa británica y norteamericana, pero menos en la francesa y alemana (ROSENTAL, 1984). El Positivismo le endorsa el sentido de Teoría del Conocimiento (Erkenntnistheorie), y, sobre todo, de Teoría del Conocimiento Científico (SÁNCHEZ GAMBOA, 1987). Con ello viene la imagen de la ciencia como paradigma del conocimiento verdadero. Siguiendo esta pauta, la palabra Epistemología suele usarse mucho para denominar la indagación filosófica sobre el conocimiento en general (sentido amplio) o científico (sentido estrecho), sus fundamentos ontológicos y gnoseológicos, su demarcación en comparación con conocimiento cotidiano común y corriente, sus métodos, técnicas, su verdad y pertinencia social.

${ }^{3}$ Thomas S. Kuhn (1997) discute eso en detalle en su estudio sobre los paradigmas, ciencia normal, ciencia extraordinaria, crisis, incomensurabilidad y revoluciones científicas en su obra "La estructura de las Revoluciones Científicas" publicado por primera vez en 1962.

\begin{tabular}{l|l|l|l} 
(C) Rev. Inter. Educ. Sup. & Campinas, SP & v.4 & n.2
\end{tabular}

AOP
mayo/ago. 2018
} 
nuestra experiencia de labor docente desde la década de los ochentas en la UNAH, la revisión de literatura y el levantamiento de documentos de la UNAH y otras instituciones, y el intercambio con colegas de Cuba y otros países.

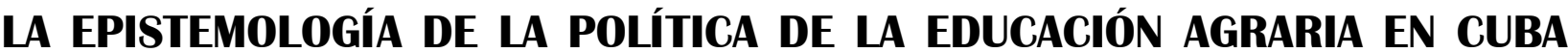 ANTES DE 1990}

Como se conoce, entre los siglos XVI y XIX la metrópoli española le había impuesto a Cuba una economía agraria esclavista o más bien semi-feudal, de plantaciones sobre todo de caña de azúcar (Saccharum officinarum). En 1901 Estados Unidos entra en la Guerra Hispano-Cubana, usurpándole a España la jurisdicción sobre Cuba, e imponiendo un régimen de dominación económica y política neocolonial, cuya agenda contempló la modernización agraria.

En 1959 triunfa el Movimiento Guerrillero "26 de Julio", liderado por Fidel Castro Ruz, Raúl Castro, Ernesto Che Guevara, y Camilo Cienfuegos. Se nacionalizan los monopolios extranjeros (latifundios) y se entrega tierras a los campesinos ${ }^{4}$. ¡La tierra es para quien la trabaja!, tal es el slogan nacionalista, anti-imperialista, anticolonial, popular, pro-campesino y democrático, socialista de la política agraria de la Revolución Cubana.

En 1961 con el propósito de destruir la Revolución e interceptar su influencia en la región, el entonces Presidente de los Estados Unidos, John Kennedy, aprobó el programa "Alianza para el Progreso", que fomenta una modernización de la agricultura auxiliada por Estados Unidos.

El gobierno revolucionario de Cuba promueve la concentración estatal de los recursos naturales, el avance y aplicación eficiente de las ciencias y tecnologías modernas y el éxito de los planes. El estado apostó al modelo de agricultura de Revolución Verde ${ }^{5}$ como directriz tecnológica de la política de desarrollo agropecuario tanto en sector estatal como cooperativo ${ }^{6}$. Elección apoyada en los acuerdos bilaterales que Cuba firmó con la URSS y bloque económico socialista de Europa del Este (CAME).

\footnotetext{
${ }^{4}$ Entre 1959 y 1961 se emiten dos leyes de Reforma Agraria, que como resultado el $40 \%$ de las tierras pasaron a propiedad del Estado y el resto $(70 \%)$ a propiedad de los trabajadores agrícolas que laboraban en el sector latifundista.

${ }^{5}$ Los apologetas y promotores de la Revolución Verde, comenzando por su pionero Norman Borlaug, suelen presentar su pertinencia para garantizar mayores producciones agrícolas en menor cantidad de tierras, satisfacer las demandas del consumo local de alimentos y el mercado, resolver el problema del hambre, y promover la paz. A la pregunta de si aun así esos problemas continúan y se han intensificado, suelen responder que la gran amenaza del planeta es el crecimiento exponencial de la población y el inadecuado uso de las tecnologías que la Revolución Verde recomienda. No faltan quienes advierten de sus impactos adversos sociales y ambientales, su contribución a la pobreza rural, el incremento de la huella ecológica, el efecto invernadero, y el cambio climático.

${ }^{6}$ No estamos hablando de Revolución Verde en el sentido del compromiso con métodos ecológicos y sostenibles de producción agrícola. Empleo del término que aparece en primera plana cuando usted hace un click búsqueda en Google.
} 
Lógicamente, el colapso del socialismo eurosoviético en 1990 fue duro para Cuba. Se interrumpe abruptamente las importaciones de insumos y maquinarias agropecuarias. Georg Bush aprueba las leyes Torricelli y Helms-Burton que recrudecen el cincuentenario bloqueo económico que impuso a Cuba en $1961^{7}$. Como resultado, los proyectos de desarrollo agropecuario basados en el enfoque de Revolución Verde se quedan a medio camino. Se reducen las importaciones y exportaciones, así como la canasta de recursos y alimentos subsidiados. Sin embargo, es justo decir que antes de la crisis de 1990 hay dificultades de la agricultura cubana antecedentes y de origen interno: el agotamiento progresivo y severo de los suelos y la biodiversidad, la insuficiencia de incentivos para vivir y trabajar en el campo, el desvío inadecuado de recursos, la especulación, así como el éxodo rural. Con la crisis de los 90 o denominada oficialmente "Periodo Especial en tiempos de paz" o "Economía de Guerra", viene la descentralización del mercado agropecuario y el fomento del desarrollo endógeno y local. En esta coyuntura se reorganiza el sistema de ciencia e innovación tecnológica. El ideal de mayor especialización, integración y aplicación de los logros en ciencia y tecnología (sobre todo biotecnológicos) encarnó en el sistema de Polos Científico-Tecnológicos. Se mantiene el sistema de los subsidios para el acceso de los productores a fertilizantes y plaguicidas químicos, y combustibles. Empero, a pesar de que el ideal de Revolución Verde no se abandona, se adopta y se refrenda el enfoque de la Agricultura Sostenible como directriz tecnológica fundamental de la política agrícola ${ }^{8}$.

No es menos cierto que antes de la crisis había emergido un movimiento profesores, estudiantes, investigadores y extensionistas y campesinos, que venían trabajando y alertando al Estado en esa dirección, y que vertiginosamente irradió y diseminó programas y proyectos de escalonamiento de prácticas agroecológicas y de agricultura sostenible con la colaboración estatal, comunitaria, local e internacional. Existe una amplia documentación nacional e internacional sobre el rumbo oportuno, exitoso y perspectivo de la Agricultura Sostenible en Cuba, sus logros y desafíos (FUNES MONZOTE et al., 2001; FUNES MONZOTE, 2009; MACHIN SOSA et al., 2010; CASIMIRO RODRIGUEZ, 2016).

En la epistemología articulada en la educación superior agropecuaria en Cuba antes de 1990 intervienen la política agraria, la política científica y tecnológica, y la política de educación superior. Los tres escenarios señalados apuestan al ideal epistemológico de la superespecialización científica, técnica, productiva, institucional, curricular y docente. El aislamiento o atomización lo más posible del objeto y el saber, se esgrime como carta de triunfo del proceso

\footnotetext{
${ }^{7}$ Esas leyes refrendan la imposición de sanciones a empresas que establecieran acuerdos comerciales con Cuba. Esta proyección extraterritorial le cierra a Cuba otras puertas de acceso a recursos y créditos.

${ }^{8}$ En correspondencia con la Agenda 21, Ley No. 81 de Medio Ambiente, dictada por el Ministerio de Ciencia, Tecnología y Medio Ambiente (CITMA), estipula el fomento de la Agricultura Sostenible, es decir la producción agropecuaria económicamente viable y socialmente aceptable, en armonía con el medio ambiente. El Decreto No. 259 de 2008 sobre entrega de tierras ociosas estipula que los nuevos tenedores están obligados a realizar prácticas de agricultura sostenible en las tierras que se le entreguen en usufructo.
} 
cognoscitivo y científico. No podríamos decir que, salvando las diferencias, ese "fenómeno perceptible en la ciencia contemporánea” no encontró suelo fértil (NUÑEZ JOVER, 2001).

Este presupuesto epistemológico acompaña al sistema educacional cubano a partir de la década del 70: la formación de un profesional actor protagonista del proyecto de la Revolución cubana y de la política de los Ministerios de la Agricultura (MINAGRI) y de azúcar (MINAZ). En correspondencia operativamente proliferan en Cuba institutos, facultades y centros agropecuarios autónomos provinciales ${ }^{9}$. Surgió así, el 7 de septiembre de 1976, el Complejo Científico-Docente Instituto Superior de Ciencias Agropecuarias (ISCAH) "Fructuoso Rodríguez Pérez". Al cual se le otorgó la función de centro rector de la mayoría de las carreras agropecuarias en Cuba. Por un lado los escenarios de ciencia y tecnología aislados que tributan a la agricultura se integran, conformando un universo de facultades, departamentos, centros e institutos de investigación exclusivamente para el desenvolvimiento agropecuario de la región occidental, integrando (RAMOS LAMAR, 1995).

El sesgo epistemológico de la atomización del objeto y el sujeto se echa a ver allí donde hay divorcio no sólo entre las especialidades agropecuarias entre sí y a su interior, sino también con el resto de los perfiles profesionales. Nuestra universidad no fue excepción. Por aquel entonces para nuestros colegas profesores de las ciencias agropecuarias no cabía ninguna duda sobre la superioridad del saber científico y tecnológico europeo-occidental, y la inferioridad del saber campesino. Esta sería un presupuesto epistemológico fundamental también articulado en la política y en el currículo. Recordamos que uno de los planteamientos muy recurrentes en nuestra universidad agraria era que el conocimiento científico da cuenta del cómo y por qué de las cosas, y que el conocimiento no científico de los campesinos, solo alcanza en el mejor de los casos a dar cuenta de cómo ocurre las cosas. Transmitimos este sesgo a través de nuestras clases de Filosofía.

Este cientificismo, y con ello otros sesgos como el tecnocratismo y la burocratización, se manifestó con fuerza en nuestra universidad agraria debido a la reticencia de los productores a la introducción de las propuestas de los productores de conocimientos científicos y transferencistas de nuevas tecnologías. Era muy común decir que conocimiento nuevo debe aplicarse, y, por lo tanto la resistencia a ello se interpretaba como limitación de los productores.

En los múltiples debates formales e informales algunos alertaban acerca de la carencia de incentivos para introducir nuevos conocimientos. O que los centros producción de conocimientos responden a demandas académicas y no a las necesidades de la producción. Y no faltaron quienes entendían que el problema estriba en las fallas de la capacitación y la adaptación local del conocimiento y la técnica. Por aquel entonces antropólogos y sociólogos estructuralistas y funcionalistas, endorsan a los campesinos rasgos cognoscitivos y socioculturales que frenan el

\footnotetext{
${ }^{9}$ Pauta este proceso la Ley No.1307-1976 (sobre el establecimiento de la estructura por especializaciones en correspondencia con la planificación del desarrollo económico y social). Como resultado, la educación agropecuaria adquirió una configuración independiente de las universidades.

\begin{tabular}{l|l|l|l|l} 
(C) Rev. Inter. Educ. Sup. & Campinas, SP & v.4 & n.2 & AOP
\end{tabular}

mayo/ago. 2018
} 
avance de la ciencia y la técnica modernas ${ }^{10}$. Es el mensaje epistemológico de que el saber agrícola científico y moderno tiene mayor alcance cognoscitivo, técnico, y práctico que el conocimiento campesino.

Obviamente, la formación de profesionales para trabajar en las gigantes empresas agropecuarias estatales, respondía a la política de modernización del MINAG), el Ministerio del Azúcar (MINAZ), y su replicas locales, es decir, las Delegaciones Provinciales. En ese entorno de monocultivos y ganadería intensiva se le otorga relevancia a las variedades de "gran" potencial genético, de alta productividad y altos rendimientos, y la utilización de altos insumos, recursos (químicos y fósiles), y maquinarias. A la luz del tiempo que ha pasado está más claro el por qué la hegemonía de la asignatura (y el Departamento) de Agroquímica en nuestra universidad, y la invocación de la formula "Nitrógeno- Potasio- Carbono" (NPK). Y esto es algo asociado al acento que se puso en la fertilización química en ese paradigma de agricultura industrial. No se pierda de vista que Cuba adquirió una fuerte capacidad insumos y equipos agrícolas, y hasta llegó a utilizar el doble de fertilizantes por hectárea que Estados Unidos. La intensidad del uso de fertilizantes ( $\mathrm{kg} / \mathrm{ha} / \mathrm{año})$ alcanzó niveles comparables con los de países europeos ${ }^{11}$.

Cuando se quiera indagar sobre los presupuestos epistemológicos de la política agraria y la política de educación agropecuaria, hay que considerar el tema de la extensión agraria. Aunque haciendo la salvedad de no existía hasta el año 2000 en Cuba un riguroso y formal sistema nacional de extensión agraria (LÓPEZ, 2005). Los contenidos de extensión agraria a penas se visualizaban. Eso no significa que haya esta función. De hecho en nuestra universidad las actividades de extensión se concentraban en la capacitación técnica.

\section{el Redimensionamiento de POLItica agrícola a PARTIR de los $90 \mathrm{y}$ SUS IMPLICACIONES EPISTEMOLÓgICAS PARA LA POĹ́TICA DE LA EDUCACIÓN AGROPECUARIA}

El cambio de política agraria en estas y otras direcciones mencionadas tuvo su repercusión epistemológica en la política de la educación agropecuaria, y sobre todo se manifestó en el contexto de los rediseños de programas: en los 80 (Planes A y B), en los 90 (Planes C y C perfeccionado), y hasta después del 2006 (Plan D). En este contexto se trabajó intensamente en la integración y reducción gradual de disciplinas y asignaturas, buscando con ello mayor interdisciplinariedad e integración de contenidos, y mayor espacio para la interacción entre la educación, la investigación, y la práctica agropecuaria a cielo abierto. El ideal epistemológico de

\footnotetext{
${ }^{10}$ A decir familarismo, localismo, tradicionalismo, conservadurismo, limitación de expectativas, y temor al cambio (SEVILLA GUZMAN, 2006).

${ }^{11}$ Al mismo tiempo, la densidad de tractores llegó a ser de 1 por cada 50 hectáreas, similar al de los países desarrollados. La infraestructura de riego y de mecanización cuatro y dos veces mayor, respectivamente, que América Latina y el Caribe (CHAN MAY LING; FREYRE ROACH, 2012, p. 77).

\begin{tabular}{l|l|l|l|l|l|}
\hline (C) Rev. Inter. Educ. Sup. & Campinas, SP & v.4 & n.2 & AOP & mayo/ago. 2018 \\
\hline
\end{tabular}
}


la super especialización pasa a tener sus días contados. La formación de un profesional integral y versátil, y capaz de trabajar colaborativamente con el sector campesino pasó a primer plano. Esto daría más chance a la a la recepción en nuestro medio del enfoque holístico e interdisciplinar de los problemas locales. Expresión de esta circunstancia es el énfasis en el desarrollo local, y la necesidad de potenciar la ciencia y la técnica a ese nivel, aparecen universidades a nivel municipal, donde el cuerpo docente está integrado no sólo por los profesores de las universidades centrales, sino también, por los profesionales del territorio.

Un slogan que caracterizaba muy bien la situación es que: ¡El municipio se convierte en una gran aula! Y así ocurría a todo lo ancho y largo de país. En esta coyuntura, a finales de los 90, y como parte del redimensionamiento de la educación superior, el ISCAH comenzó a llamarse Complejo Científico-Docente Universidad Agraria de la Habana (UNAH) "Fructuoso Rodríguez Pérez". Y detrás de este acontecimiento podríamos deducir que los aires de super especialización cognoscitiva soplan con menos intensidad. Después, en el 2000 aparecen las Sedes Universitarias Municipales (SUM) adjuntas a las universidades, que hoy se llaman Filiares Universitarias Municipales (FUM), integradas a Centros Universitarios Municipales (CUM) (PÉREZ ZABALLA et al, 2016). Por doquier vemos aires de integración de conocimientos, así como de interdisciplinariedad en el currículo, en los proyectos de investigación, y en las actividades de extensión. Ahora, cuando se llama UNAH contempla esas carreras pero también las de Contabilidad, Estudios Socioculturales, Cultura Física y Deportes, e Informática.

A esto contribuye un cambio de actitud académica en favor de la innovación participativa, que tengan en cuenta los criterios de los agricultores en la toma de decisiones y evaluación del desempeño productivo. De hecho la política agraria, la política de ciencia y técnica, y la política ambiental después del 90 estipula la integración de los logros científicos y técnicos con los conocimientos locales tradicionales de la población y los recursos genéticos, propiciando la participación directa de las comunidades locales en la concepción, desarrollo y perfeccionamiento de los sistemas de producción. En este proceso papel crucial viene jugando el Grupo de Agricultura Orgánica (GAO) de nuestra institución ${ }^{12}$.

Con la Agroecología vienen replanteamientos que empujan a la crítica sistemáticas de los presupuestos epistemológicos de la Revolución Verde y a la elaboración de referentes epistemológicos de la Agricultura Sostenible. Dualismos como la dicotomía objeto-sujeto (SERRA BORSATTO; SIMÕES DO CARMO, 2012, p. 714) pasan a ser fuertemente cuestionados.

\footnotetext{
${ }^{12}$ A la sombra de este grupo se creó el Grupo de Estudios de Agroecología y Agricultura Sostenible (CEAS) a finales de los 80. En los 90 se aprueba la Agroecología en el Tribunal Nacional para la evaluación de las Tesis de Doctorado en Agronomía. Y en esa misma época comienza a ofertarse la Maestría de Agroecología y Agricultura Sostenible en la UNAH, años después en la Facultad de Agronomía de la Universidad de Villa Clara, y actualmente también en la Universidad de Pinar del Río, y con versiones en Ecuador, Bolivia, y Venezuela.
}

\begin{tabular}{l|l|l|l|l|l} 
(C) Rev. Inter. Educ. Sup. & Campinas, SP & v.4 & n.2 & AOP & mayo/ago. 2018 \\
\hline
\end{tabular}


Cabe mencionar que en la actualidad existe en la UNAH el Grupo de Extensión Agraria y Agricultura Sostenible que promueve por toda Cuba la perspectiva extensionista inspirada en la Educación Popular de Paulo Freire y el pensamiento agroecológico (LÓPEZ, 2005). Resultando así la organización de actividades de extensionismo participativo, horizontal, y dialógico, que ponen en tela de juicio la epistemología cientificista, tecnocrática, paternalista, transferencista y ofertista de la extensión agraria en Cuba antes de 1990. No podemos decir que en Cuba ese paradigma de extensionismo agrario haya desaparecido del todo.

La enseñanza de las Ciencias Humanas promovió una epistemología con la política agraria, de ciencia y tecnología, y educacional del Estado. En la UNAH la discusión fundamental tenía que ver con la demanda de que el Marxismo sirviera para resolver problemas concretos y prácticos del perfil profesional agropecuario.

El insuficiente vínculo de nuestras asignaturas con el perfil profesional ya viene anunciadose desde la hora en punto en que se resalta la función ideológica y política cultural de los estudiantes. Al calor de los rediseños de programas de estudios en las carreras agropecuarias el debate se intensifica. Y entonces salen a flote sesgos epistemológicos de nuestra asignatura que explicaban ya no sólo su complicidad con la Revolución Verde, sino también la opinión muy difundida entre nuestros colegas agropecuarios de que el conocimiento filosófico en nada contribuye a su trabajo.

Con ello vienen las críticas al cientificismo y al tecnocratismo. Sería interesante explorar en otros trabajos cómo estos sesgos tienen que ver con la resistencia de la comunidad científica ante el paradigma emergente de la Agricultura Sostenible y la conservación del paradigma de la Revolución Verde.Como habíamos dicho arriba, una de las cuestiones más debatidas sobre la enseñanza de las Ciencias Humanas en Cuba fue su desconexión de los perfiles profesionales de las carreras. En el ámbito de la enseñanza y la investigación agropecuaria, eso está muy asociado al determinismo tecnocrático y al verticalismo en el ámbito de la producción de conocimientos y la transferencia de tecnologías de la Revolución Verde. A finales de los 90 se aprueba por el Ministerio de Educación Superior (MES) que la enseñanza de las Ciencias Humanas se diseñe a partir, de las necesidades de la formación profesional por cada una de las carreras. En aquel entonces adquirió auge el debate sobre la necesidad de mayor vínculo de la Filosofía con el perfil de las carreras, pero salvando que esa "perfilización"13 no terminará en la mera y forzada aplicación o ejemplificación banal y vulgar de los contenidos filosóficos.

Fue precisamente en este contexto que programa de enseñanza del Marxismo en la UNAH entronca con el movimiento agroecológico en apogeo. En aquel entonces no faltaron los cuestionamientos a la apología del saber científico y tecnológico y la estigmatización del saber campesino, lo cual implicaba, como muy bien dice un autor que:

${ }^{13}$ Palabra que se utilizaba mucho entre nosotros en Cuba

\begin{tabular}{l|l|l|l|l|l} 
(C) Rev. Inter. Educ. Sup. & Campinas, SP & v.4 & n.2 & AOP & mayo/ago. 2018 \\
\hline
\end{tabular}


[...] mediante el fomento de la agroecología podemos contribuir la recomposición de un metabolismo social que expresa la sabiduría y permanente reactualización en una relación sociedad-naturaleza integral, que supera el antropocentrismo que comparten el capitalismo y el marxismo ortodoxo. (SEVILLA GUZMAN, 2011, p. 135).

Hoy en día en la misma dirección apuntan quienes están desarrollando una concepción de la Economía Ambiental y la Sociología inspirada en el Eco-Marxismo (LEFF, 2011). La enseñanza del Marxismo en nuestra universidad comenzó a incorporar esos enfoques en el programa docente.

Al calor de los procesos de transformación de la enseñanza de la Filosofía en Cuba, se aprueba ministerialmente la introducción de los Problemas Sociales de la Ciencia y la Tecnología (PSCT) como asignatura cierre e integración de las asignaturas precedentes de la disciplina MarxismoLeninismo. El mensaje que lanza esta política es ante todo epistemológico: la necesidad del cambio de la imagen de la ciencia y la tecnología. Esta materia de PSCT es la forma en que se recepcionó en Cuba la reflexión globalizada en materia de Epistemología, Cienciología (FIGAREDO CURIEL, 2002), Filosofía de la Ciencia, Filosofía de la Tecnología, Sociología del Conocimiento, los Estudios Sociales de la Ciencia y la Tecnología o Ciencia, Tecnología y Sociedad (Estudios CTS). En uno de los fragmentos del texto básico actual de esta asignatura en todos los centros universitarios de Cuba, su autor, el Dr Jorge Núnez Jover, principal promotor de esos estudios, escribe:

En este libro trato de fundamentar la idea según la cual la educación científica no puede apoyarse en imágenes caducas de la ciencia y la tecnología y mediante la discusión de la bibliografía disponible intento presentar imágenes alternativas, más actualizadas. Para ello insisto en las interrelaciones de la ciencia y la tecnología y del complejo que ellas constituyen (tecnociencia) con la sociedad, desplazando las visiones más tradicionales, lineales y optimistas. También argumento la complejidad epistemológica de la ciencia que obliga a repensar concepciones simplificadas sobre la racionalidad, el método científico, la objetividad y la verdad. Espero que la discusión sobre los aspectos institucionales, sociales y culturales propios del trabajo científico contribuya a enriquecer las imágenes de la tecnociencia que los canales educativos, formales e informales, suelen transmitir (NÚÑEZ JOVER, 2001, p. 5).

Este enfoque pone en tela de juicio las imágenes optimistas, benefactoras, artefactual, romántica, positivista, cientificista, desarrollista, objetivista y universalista de la ciencia y la tecnología, el progreso científico, el progreso tecnológico, y sus relaciones con el progreso social. Al replantearse el status epistemológico de la ciencia, también se cuestiona la definición de la tecnología como mera ciencia aplicada, así como la supuesta neutralidad de ambas. Pasa a primer plano la tesis de que las ciencias y las tecnologías son empresas e instituciones sociales, condicionadas por el contexto social, económico, político, y cultural, y cuyo desarrollo se acompañan de impactos sociales y ambientales. Operativamente se infiere que no todo lo científicamente y técnicamente posible debe ser considerado socialmente viable, y, por lo tanto, también, la necesidad de la vigilancia, monitoreo, y fiscalización pública de la ciencia, ya no solo cuando el resultado (el descubriendo o nuevo conocimiento ya está consumado), sino también, aun antes de proyectarse, y más aún, cuando se aplica. Todos estos temas fueron potenciados por

\begin{tabular}{|l|l|l|l|l|l|}
\hline (C) Rev. Inter. Educ. Sup. & Campinas, SP & v.4 & n.2 & AOP & mayo/ago. 2018 \\
\hline
\end{tabular}


la Cátedra de Ciencia, Tecnología y Sociedad de la Universidad de la Habana (UH) y los autores de este artículo llevamos esta reflexión al campo de la agricultura (FREYRE ROACH; RAMOS LAMAR, 1994). Justo es decir que teníamos como antecedentes los trabajos del profesor de Filosofía Dr. Carlos Valtuille sobre conceptos de "bioesfera" y "noosfera" elaborados por sobre el concepto de biosfera Vladimir Vernadsky (1863-1945) y Pierre Teilhard de Chardin (1881 1955).

El curso de PSCT viene siendo un escenario docente de gran importancia para canalizar las discusiones epistemológicas que continúan debatiéndose en Cuba a raíz de que el gobierno está apostando a la introducción de nuevas tecnologías como el caso de la Agricultura de Precisión, y sobre todo los Modificación Genética de Organismos (FUNEZ MONZOTE; FREYRE ROACH, 2009).

La repercusión epistemológica que viene teniendo el curso de PSCT en las universidades cubanas, y, por ende, en nuestra institución se expresa también en que sus contenidos resultan requisitos para el cambio de categorías docentes (Profesor asistente, auxiliar y titular) y científicas (investigador agregado, auxiliar y titular), y para optar por el Grado Científico de Doctor en todas las especialidades científicas. Hasta la fecha, no hay otro curso que tenga esa posición privilegiada dentro del ámbito de la enseñanza superior agropecuaria en Cuba. A la par, vemos que profesores de Filosofía comienzan a insertarse en los temas de investigación agropecuaria, y profesores de ciencias agropecuarias participan entusiastamente en investigaciones sobre cuestiones filosóficas, ético-profesionales, económicas y políticas relacionadas sobre todo con su perfil profesional y laboral.

\section{CONSIDERACIONES FINALES}

En Cuba la Epistemología o la visión de la ciencia y la tecnología que subyace al pensamiento y la gestión agropecuaria de Revolución Verde, pierde hegemonía, en medio de las circunstancias del desarrollo agropecuario cubano: la crisis de los 90, las reformas de la política del gobierno, el auge del movimiento agroecológico, y las transformaciones de la enseñanza de las Ciencias Humanas. Pero esa pérdida no es absoluta porque aún persiste entre gestores de la política agropecuaria y el claustro de los centros de educación agropecuaria la mentalidad romántica y nostálgica respecto a ese enfoque, y la percepción de que el fomento de la agricultura sostenible es meramente táctico y coyuntural.

En el giro epistemológico que se está desarrollando en nuestra universidad se conjugan múltiples factores. Ciertamente, los cambios de la política agraria por las circunstancias traen consigo un escenario favorable para el replanteamiento de la imagen de la ciencia y la tecnología. Más aun, porque con ello vienen rediseños del currículo de las carreras agropecuarias y del curso de Filosofía. 
De otro lado, en nuestros claustros, antes de esas circunstancias ya existe una masa crítica de profesores cuyos trabajos estaban anunciando e indicando la necesidad de cambio en la imagen de la ciencia y la tecnología, y que el giro epistemológico es impostergable.

\section{REFERENCIAS}

ALTIERI, Miguel; FUNES MONZOTE, Fernando Rafael. La paradoja de la agricultura cubana. CEPRID, [s.1.], Jueves 12 abr. 2012. Disponible en:

<http://www.nodo50.org/ceprid/spip.php?article1395 >. Acceso en: 11 abr. 2015.

BLANCHÉ, Robert. A epistemologia. 4. ed. Lisboa: Editorial Presença, 1988. 161p.

BREILH, Jaime. Investigación agraria: por qué la urgencia de una epistemología crítica? Con qué tipo de ciencia queremos trabajar hacia otra realidad agraria? Ecuador: Universidad Andina "Simón Bolívar", 2005. 13p.

CASIMIRO RODRÍGUEZ, Leydi. Bases metodológicas para la resiliencia socioecológica de fincas familiares en Cuba. 2016. 244 f. Tesis (Doctora en Agroecología) - Universidad de Antioquia, Facultad de Ciencias Agrarias. Medellín, 2016.

CHAN, May Ling; FREYRE ROACH, Eduardo Francisco. Unfinished Puzzle: Cuban agriculture - the challenges, lessons and opportunities. Disponible en:

<https://foodfirst.org/publication/unfinished-puzzle/>. Acceso en: 12 jan. 2012.

FIGAREDO CURIEL, Francisco. La tradición cienciológica en el estudio de la ciencia. Llull: Revista de la Sociedad Española de Historia de las Ciencias y de las Técnicas, Zaragoza, v.25, n.54, p. 621-642, 2002.

FREYRE ROACH, Eduardo Francisco; RAMOS LAMAR, Adolfo. Ciencias Agrarias y Sociedad. En: NÚÑEZ JOVER, Jorge. Problemas sociales de las ciencias y las tecnologías. C. Habana: Editorial Félix Varela, 1994, p. 15-28.

FUNES-MONZOTE, Fernando Rafael et al. Transformando el campo cubano: avances de la agricultura sostenible. La Habana: Asociación de Técnicos Agrícolas y Forestales; Editorial Asociación Cubana de Técnicos Agrícolas y Forestales, 2001.

FUNES-MONZOTE, Fernando Rafael. Agricultura con futuro. La alternativa agroecológica para Cuba. Matanzas/Cuba: Estación Experimental "Indio Hatuey" / Universidad de Matanzas, 2010 . 196p.

FUNES-MONZOTE, Fernando Rafael.; FREYRE ROACH, Eduardo Francisco. Transgénicos: quien gana, quien pierde. Texto para un debate en Cuba. Habana: Centro Félix Varela de la Habana / Editorial Acuario, 2009. 
SANCHEZ GAMBOA, Silvio Ancisar. Epistemologia da pesquisa em educação: estruturas logicas e tendencias metodologicas. 1987. 229 f. Tese (Doutorado) - Universidade Estadual de Campinas, Faculdade de Educação, Campinas, SP. Disponible em:

<http://www.repositorio.unicamp.br/handle/REPOSIP/251514>. Acceso en. 20 set. 2017.

GUADARRAMA GONZÁLEZ, Pablo. Fundamentos filosóficos y epistemológicos de la investigación. Disponible em: <http://www.archivochile.com.> Acceso em: 20 set. 2017.

KUHN, Thomas Samuel. A estrutura das revoluções científicas. 5. ed. São Paulo: Perspectiva, 1997. 257 p.

LEFF, Enrique. Sustentabilidad y racionalidad ambiental: hacia "otro" programa de sociología ambiental. Revista Mexicana de Sociología, Mexico, v.73, n.1, p. 5-46, jan./mar. 2011.

LÓPEZ, Teodoro. Organización y estructura del sistema de extensión agraria (SEA) en Cuba. Revista Computarizada de Producción Porcina, La Habana, v.12, n.1, p. 22-26, 2005.

MACHÍN SOSA, Braulio et al. Revolución agroecológica: el Movimiento de Campesino a Campesino de la ANAP de Cuba. La Habana: ANAP, 2010.

NÚÑEZ JOVER, Jorge. La ciencia y la tecnología como procesos sociales. La Habana: Editorial Feliz Varela, 2001.

NÚÑEZ JOVER, Jorge. Problemas sociales de las ciencias y las tecnologías. La Habana: Editorial Félix Varela, 1994, p. 15-28.

PÉREZ ZABALLA, Leonor et al. Impacto de la formación en las Filiales Universitarias Municipales. Experiencias en Mayabeque y Artemisa. Congreso Universidad, Ciudad Habana, v. 5, n. 1, p. 159-176, 2016.

RAMOS LAMAR, Adolfo. A crise do bloco socialista e a politica de C\&T em Cuba: o caso do Instituto Superior de Ciências Agropecuárias de Havana. 1995. 134 f. Dissertação (Mestrado) - Universidade Estadual de Campinas, Instituto de Geociências, Campinas, SP. Disponible em: 〈http://www.repositorio.unicamp.br/handle/REPOSIP/286699>. Acceso en: 20 set. 2017.

ROSENTAL, Moisevich Mark; IUDIN FEDOROVICH, Pavel. Diccionario filosófico. La Habana: Editorial Ciencias Sociales, 1984.

SERRA BORSATTO, Ricardo; SIMÕES DO CARMO, Maristela. Agroecologia e sua epistemologia. Interciencia, Caracas, v. 37, n. 9, p. 711-71, set., 2012.

SEVERINO, Antônio Joaquim. Integrar cultura e humanismo: desafio pedagógico da Filosofia no Ensino Superior. Educar em Revista, Curitiba, n. 46, p. 21-35, out./dez. 2012. 
SEVILLA GUZMÁN, Eduardo. Sobre los orígenes de la agroecología en el pensamiento marxista y libertario. La Paz: Plural editores, 2011.

SEVILLA GUZMÁN, Eduardo. De la sociología rural a la Agroecología. Barcelona: Icaria Editorial-Junta deAndalucía, 2006.

\section{${ }^{\mathrm{i}}$ Sobre los autores}

\section{Adolfo Ramos Lamar}

E-mail: ajemabra@yahoo.com.br / ORCID: http://orcid.org/0000-0003-1164-1172

Universidade Regional de Blumenau - Brasil

Doutor em Educação em Política Científica e Tecnológica pela Universidade Estadual de Campinas [UNICAMP].

2 Eduardo Francisco Roach

E-mail: freyre.roach2016@gmail.com / ORCID: http://orcid.org/0000-0002-2267-1564

Universidade Regional de Blumenau - Brasil

Pós-doutor em Educação pela Universidade Estadual de Campinas [UNICAMP]. 